\title{
Patient Satisfaction with the New Interferon Beta-1b Autoinjector (BETACONNECT ${ }^{\mathrm{TM}}$ )
}

\author{
Tjalf Ziemssen · Lauren Sylvester · Mark Rametta $\cdot$ Amy Perrin Ross
}

To view enhanced content go to www.neurologytherapy-open.com

Received: September 22, 2015 / Published online: October 27, 2015

(C) The Author(s) 2015. This article is published with open access at Springerlink.com

\begin{abstract}
Introduction: Multiple sclerosis (MS) typically requires life-long management with disease-modifying therapies (DMTs). Many DMTs require regular self-injection, and can be associated with injection site reactions, pain, and needle/injection phobia-but these can be addressed by improvements in autoinjector design. The aim of this study was to investigate patient satisfaction and preference for BETACONNECT ${ }^{\mathrm{TM}}$ (Bayer Pharma AG), a novel interferon beta-1b autoinjector.
\end{abstract}

Methods: Patients in Germany performing self-injections using BETACONNECT took part

Electronic supplementary material The online version of this article (doi:10.1007/s40120-015-0036-y) contains supplementary material, which is available to authorized users.

\section{T. Ziemssen ( $\square)$}

Department of Neurology, Centre for Clinical Neurosciences, University Hospital Carl Gustav Carus at the Technical University of Dresden, Dresden, Germany

e-mail: tjalf.ziemssen@uniklinikum-dresden.de

L. Sylvester · M. Rametta

Bayer HealthCare Pharmaceuticals, Whippany, NJ, USA

A. P. Ross

Loyola University Chicago, Maywood, IL, USA in the study. Data were collected through an online 15-min structured survey. Participants rated their experience with BETACONNECT on a 6-point scale and those satisfied with BETACONNECT were asked to describe the reason using a free-text box.

Results: One-hundred and eighteen patients with MS completed the survey. Ninety percent preferred BETACONNECT to their previous injection method (only 4\% previously used manual injections, so most had previously used other autoinjectors). Ninety-two percent were very confident/confident in their ability to perform an injection using BETACONNECT. The most common free-text responses to "Why are you satisfied with the BETACONNECT $^{\mathrm{TM}}$ autoinjector?" were ease of use $(46 \%)$, less irritation/pain at the injection site (33\%), and smoother injections (24\%). Features considered most useful were automated injections (98\%), adjustable injection speed (98\%), and adjustable injection depth (98\%). Ninety-seven percent thought it was easy to know when an injection was complete and 95\% agreed/ strongly agreed it was easy to learn to use the autoinjector. Seventy-three percent agreed that 
the quietness and effortlessness of the BETACONNECT reduced their level of injection anxiety, 92\% that its size and shape makes it easy to handle during injections, and $67 \%$ that it decreases injection site pain. Eighty percent of those using the reminder function thought they were less likely to miss an injection.

Conclusion: Patients with MS self-injecting interferon beta- $1 \mathrm{~b}$ expressed a high level of satisfaction and preference for BETACONNECT. Thus, BETACONNECT represents a valid option to improve patients' overall injection experience.

Funding: Bayer HealthCare Pharmaceuticals.

Keywords: Beta-interferons; Disease-modifying therapies; Electronic autoinjector; Patient survey; Relapsing-remitting multiple sclerosis

\section{INTRODUCTION}

Multiple sclerosis (MS) is a chronic and debilitating autoimmune disease affecting the central nervous system, with a worldwide prevalence of approximately 33 cases per 100,000 individuals [1]. Typically, the first manifestation of MS occurs when patients are in their 20 or $30 \mathrm{~s}$, and it is normal to live with MS for about 30 or 40 years [2, 3]. Medication for MS usually includes long-term management with disease-modifying therapies (DMTs) such as interferon beta-1b, which can alter the pathological immune responses associated with MS, prevent relapses, and slow disease progression [4].

Other than the development of new treatments, improving the management of MS can focus on a number of factors, including the delivery systems of existing drug therapies. Many of the currently approved DMTs require patients to perform regular self-injections, which can be associated with injection site reactions, pain, and needle phobia or other injection anxieties. However, the use and ongoing development of autoinjectors have the potential to reduce the incidence of injection site reactions $[5,6]$, reduce needle phobia and patients' anxiety about self-administered injections [7], and increase adherence [8]. This is supported by new autoinjector designs that could make the injection process easier, particularly for patients with visual, dexterity or cognitive problems (for example, by incorporating electronic reminders to overcome forgetfulness) $[5,6,9]$.

A variety of injection devices for many DMTs have been developed and evaluated with respect to patient satisfaction [10-15]. However, the new fully electronic BETACONNECT ${ }^{\mathrm{TM}}$ (Bayer Pharma AG) autoinjector evaluated in the current study encompasses many advances in autoinjector design and technology as outlined in the following section, which may further enhance patient comfort, satisfaction and adherence, and is hoped to further improve management of MS. Thus, the aim of the current study was to investigate patient satisfaction and preference for this new interferon beta- $1 b$ autoinjector. We hypothesized that patients would be more satisfied with the BETACONNECT autoinjector in comparison with other methods they used previously to inject interferon beta-1b. We also aimed to investigate the reasons underlying patient satisfaction.

\section{METHODS}

\section{BETACONNECT $^{\mathrm{TM}}$ Autoinjector}

The BETACONNECT autoinjector (Fig. 1) is fully electronic and offers many improvements over older mechanical devices used for the delivery of other MS therapies. It has an intuitive user 

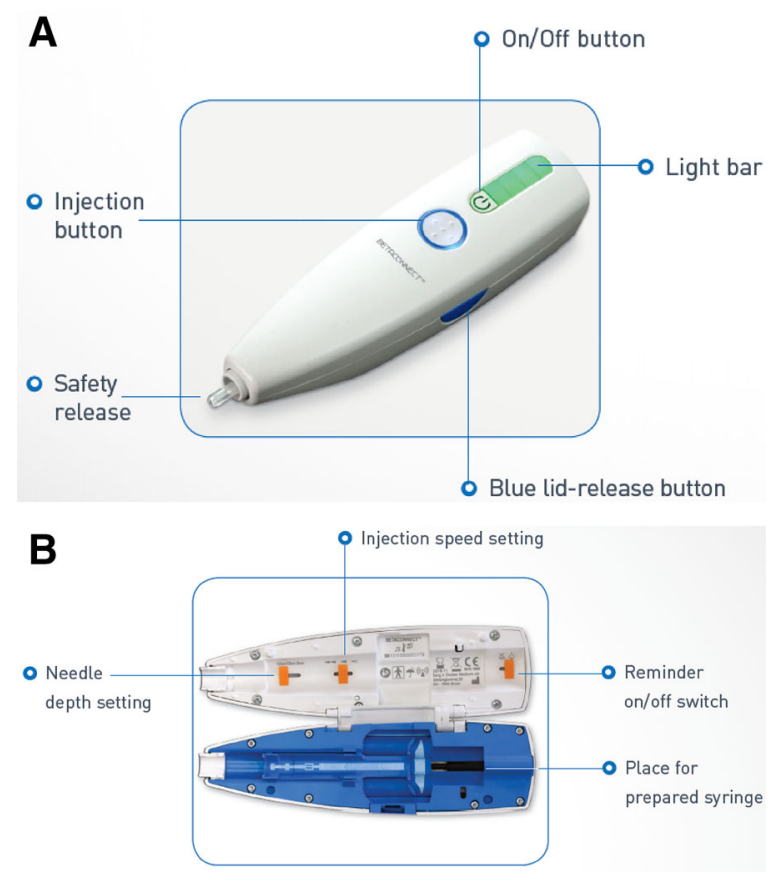

Fig. 1 The BETACONNECT ${ }^{\mathrm{TM}}$ electronic autoinjector. a The ergonomic design makes the device easy to handle and allows one-handed injections, with the needle hidden during the entire injection process, and audible and visible indicators of battery status, safety release, and dose reminder functions. $\mathbf{b}$ The syringe for interferon beta- $1 \mathrm{~b}$ release is placed within the autoinjector, and the interior features injection setting controls

interface and ergonomic design making it easy to handle and allowing one-handed injections. It features adjustable injection speed and depth to allow individual injection settings, and a low-force safety release to ensure the device is positioned correctly at the time of the injection. The BETACONNECT autoinjector's electronic injection is nearly silent and features four-phase injection technology: (1) automatic needle insertion; (2) delivery of the medication; (3) dwell time, when the needle remains in the skin momentarily, reducing the risk of an injection site reactions; and (4) automatic needle retraction. The autoinjector then provides both optical and audible signals of injection completion. It also features audible and visible indicators of battery status and a dose reminder function. Finally, this novel device automatically records data such as injection date and time, injection depth, injection speed, and injection volume as patients perform injections. It also offers the possibility to share data with healthcare providers via an app called myBETAapp $^{\text {TM }}$ (Bayer Pharma AG) and the Navigator, a dashboard monitoring application, to enhance communication between patients and healthcare professionals. Table 1 shows some of the key characteristics of the BETACONNECT autoinjector $[12,16-21]$.

\section{Participants}

Patients using BETACONNECT in Germany were invited to participate in the survey, through either invitations sent by mail or invitation cards distributed by BETAPLUS ${ }^{\circledR}$ nurses (Bayer-sponsored nurses who train patients with MS and help them to manage their disease). Participation required use of BETACONNECT for at least 2 weeks, use of interferon beta- $1 \mathrm{~b}$ for at least 6 months, and performance of self-injections the majority of the time. All patients were aged 18 years or older and had been diagnosed with MS more than 6 months ago.

\section{Survey Instruments and Data Collection}

Data were collected through an online 15-min structured survey. Participants rated the usefulness of features offered by BETACONNECT on a 6-point scale which ranged from 1 (very useless) to 6 (very useful), with results presented as the percentage of those who rated each feature "useful" or "very useful" (rating of 5 or 6). Respondents were able to skip questions for features they were unaware of and/ or did not have enough experience with to provide a response. Participants also rated 
Table 1 Key characteristics of the BETACONNECT ${ }^{\mathrm{TM}}$ autoinjector $[12,16-21]$

\begin{tabular}{|c|c|}
\hline Feature & Main rationale/benefit \\
\hline Ergonomic design & $\begin{array}{l}\text { Allows ease of handling and one-handed operation: useful for patients with } \\
\text { reduced manual dexterity (about } 79 \% \text { of patients with MS) [16] or short } \\
\text { "thumb reach" (particularly a problem for some women) [17] }\end{array}$ \\
\hline Intuitive user interface & $\begin{array}{l}\text { Simplicity and ease of use are considered important features by patients with } \\
\text { MS [12]. May be helpful as about } 65 \% \text { of patients with MS have cognitive } \\
\text { impairment which can accrue in all MS sub-types [18] }\end{array}$ \\
\hline Safety release & $\begin{array}{l}\text { Important owing to reduced manual dexterity in the majority of patients with } \\
\text { MS (as noted above) }\end{array}$ \\
\hline $\begin{array}{l}\text { Automatic needle insertion/retraction and } \\
\text { needle hidden at all times }\end{array}$ & $\begin{array}{l}\text { Avoidance of needle phobia and reduce the risk of inadvertent needle-stick } \\
\text { injury [19] }\end{array}$ \\
\hline End-of-dose indicators (visible and audible) & Considered important by patients with MS [12] \\
\hline Adjustable injection speed and depth & $\begin{array}{l}\text { Regarded as important features, and lack of control of injection process } \\
\text { including speed and depth given as a reason for not using an injection } \\
\text { device [12] }\end{array}$ \\
\hline Injection reminder & $\begin{array}{l}\text { Forgetting to take medications for MS is the most common reason for } \\
\text { non-adherence to MS drug therapy }[20,21]\end{array}$ \\
\hline
\end{tabular}

$M S$ multiple sclerosis

BETACONNECT on its intuitiveness, ease of use, and its effect on their injection experience. Ratings were provided on a 6-point scale ranging from 1 (strongly disagree) to 6 (strongly agree), with results presented as the percentage of those who "agreed" or "strongly agreed" (rating of 5 or 6). Participants satisfied with BETACONNECT were asked to describe the reason why they are satisfied with the autoinjector in an open-ended free-text box. The open-ended free-text box allowed participants to describe their feelings about the device completely unaided, reducing the potential influence of the survey design. The answers provided were coded by frequency that they were mentioned. Patients were also asked to rate the ease of performing injections (rating from very difficult to very easy) and how confident they were in performing an injection with the BETACONNECT (rating from very unconfident to very confident). The survey was created and managed by an independent market research company, and funded by Bayer HealthCare Pharmaceuticals, Inc., Whippany, NJ, USA. Respondents were offered a gift card valued at $€ 10$ for their participation.

All procedures followed were in accordance with the 1964 Declaration of Helsinki and its subsequent revisions. Informed consent was obtained from all patients included in the study. This article describes a non-interventional study, and so does not involve any new studies of human or animal subjects performed by any of the authors.

\section{RESULTS}

\section{Demographic Characteristics}

A total of 118 respondents with MS agreed to participate, and completed the survey. The demographic characteristics of survey 
participants are shown in Table 2. Nearly three-quarters (72\%) of respondents were female, average age was 47.2 years, and the majority (69\%) had been using the autoinjector for more than 1 month. Before using BETACONNECT, the majority of participants had been administering interferon beta- $1 b$ using a different autoinjector (BETACOMFORT $^{\circledR} \quad 56 \%$ BETAJECT COMFORT $^{\circledR} 39 \%$, BETAJECT LITE $^{\circledR} 14 \%$; all Bayer Pharma AG) or manual injection with a syringe (4\%).

Table 2 Demographic characteristics of survey participants $(n=118)$, including previous injection $\operatorname{method}(s)$

\begin{tabular}{|c|c|}
\hline Characteristic & Number (\%) \\
\hline Females & $85(72 \%)$ \\
\hline \multicolumn{2}{|l|}{ Age } \\
\hline$<36$ years & $13(11 \%)$ \\
\hline $36-45$ years & $18(15 \%)$ \\
\hline $46-55$ years & $35(30 \%)$ \\
\hline $56-65$ years & $24(20 \%)$ \\
\hline$\geq 60$ years & $1(1 \%)$ \\
\hline \multicolumn{2}{|c|}{ Previous injection method $(s)^{a}$} \\
\hline BETACOMFORT $^{\circledR}$ & $66(56 \%)$ \\
\hline BETAJECT $^{\circledR}$ Comfort & $46(39 \%)$ \\
\hline BETAJECT $^{\circledR}$ Lite & $16(14 \%)$ \\
\hline Manual, no autoinjector & $5(4 \%)$ \\
\hline No answer & $4(3 \%)$ \\
\hline \multicolumn{2}{|c|}{ Length of time using BETACONNECT ${ }^{\mathrm{TM}}$} \\
\hline$<1$ month & $37(31 \%)$ \\
\hline$>1$ month & $81(69 \%)$ \\
\hline No answer & $0(0 \%)$ \\
\hline
\end{tabular}

${ }^{a}$ Multiple selections were allowed to cover any previous injection method the patient had used, thus these percentages total more than 100\%

\section{Overall Perceptions of BETACONNECT ${ }^{\mathrm{TM}}$}

The overall ratings for the autoinjector were very positive, with $90 \%$ of respondents stating that they preferred BETACONNECT to their previous injection method and 92\% reporting that they were very confident or confident in their ability to perform an injection using the BETACONNECT autoinjector (Fig. 2). A total of 85 patients who were satisfied or very satisfied with the BETACONNECT device, responded to the open-ended question "Why are you satisfied with the BETACONNECT ${ }^{\mathrm{TM}}$ autoinjector?" The most common reasons given were its ease of use (46\%), less irritation/pain at the injection site (33\%), and smoother injections (24\%; Fig. 3). Patients also appreciated the reminder function (13\%), ability to personalize the injection speed and depth (12\%), ease of handling (9\%), and quieter injections (6\%).

The features of BETACONNECT that were rated as most useful (i.e., rated "useful" or "highly useful") are shown in Fig. 4. Features considered as most useful (by 98\% of survey responders in each instance) were automated injections, adjustable injection speed, and adjustable injection depth. Features that help guide the injection process such as the self-check function (which communicates that the autoinjector is functioning and ready for use) and the end-of-dose indicator (signified acoustically and visually) were also rated as "useful" or "very useful" by more than 9 in 10 respondents using these features.

\section{Ease of Use}

Responses related to the intuitiveness and ease of use of the autoinjector were also favorable: $97 \%$ thought it was easy to know when an injection was complete and 95\% agreed/ strongly agreed it was easy to learn to use the 


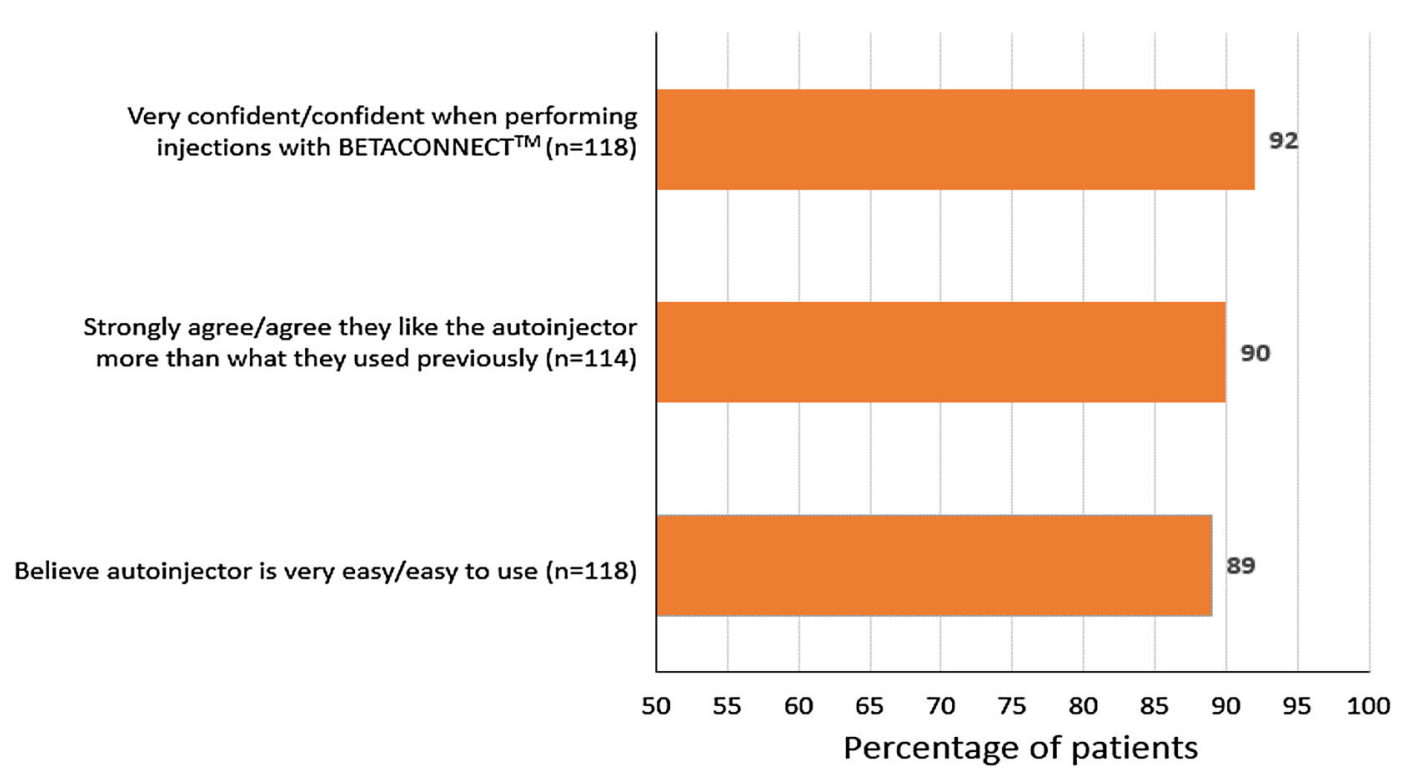

Fig. 2 Overall impressions of the BETACONNECT ${ }^{\mathrm{TM}}$ autoinjector. Base: total respondents, excluding those who answered "don't know"

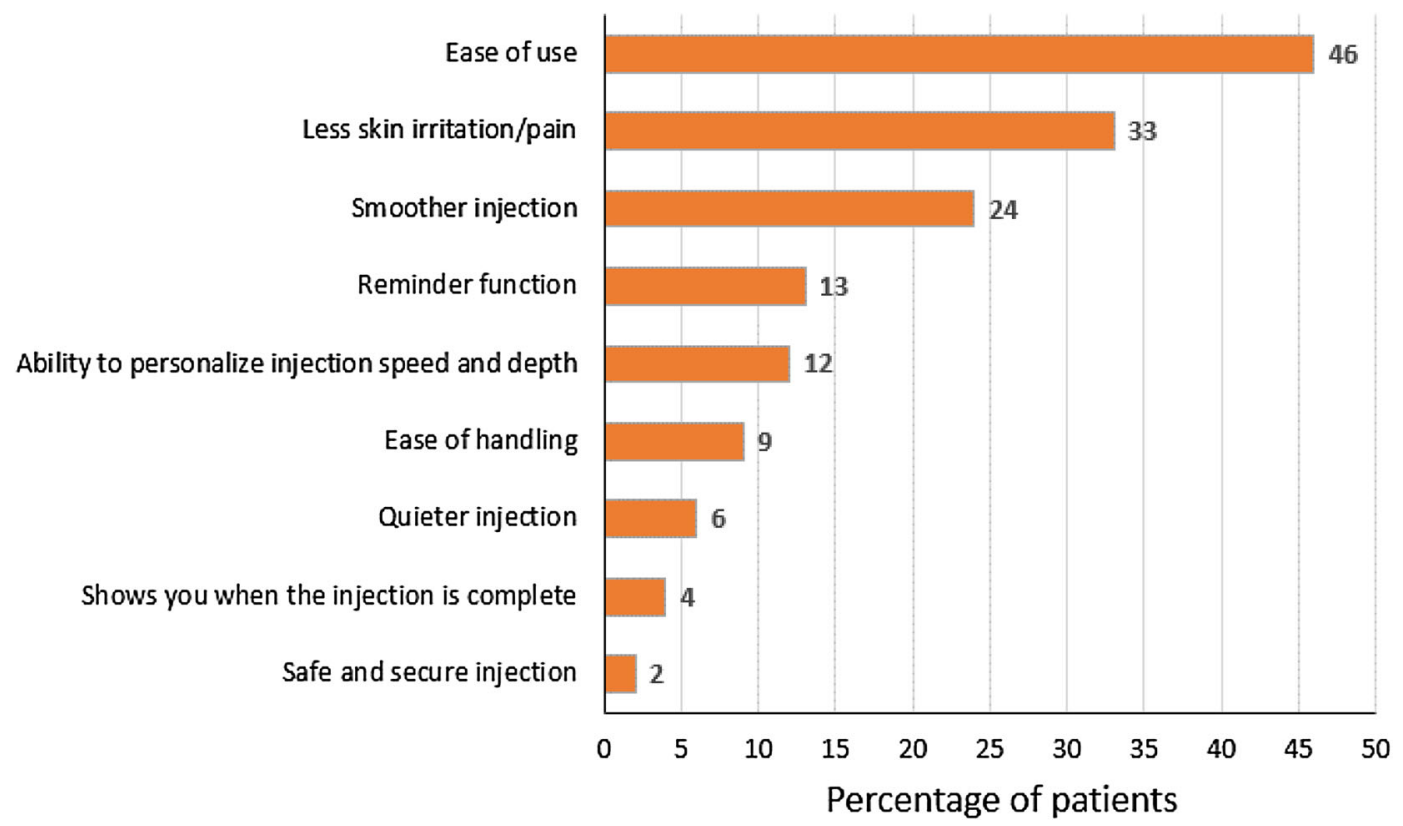

Fig. 3 Primary reasons for satisfaction with BETACON$\mathrm{NECT}^{\mathrm{TM}}$ (unaided responses to open-ended questions, $n=$ 85). Base: respondents satisfied with BETACONNECT ${ }^{\mathrm{TM}}$

autoinjector (Fig. 5). Likewise, 94\% agreed/ strongly agreed that the lights and buttons are self-explanatory, and 91\% that the light bar and who answered: "Why are you satisfied with the BETACONNECT $^{\mathrm{TM}}$ autoinjector??

makes it easy to monitor the progress of an injection. Among those aware of the contact sensor $(n=110), 85 \%$ agreed/strongly agreed it 


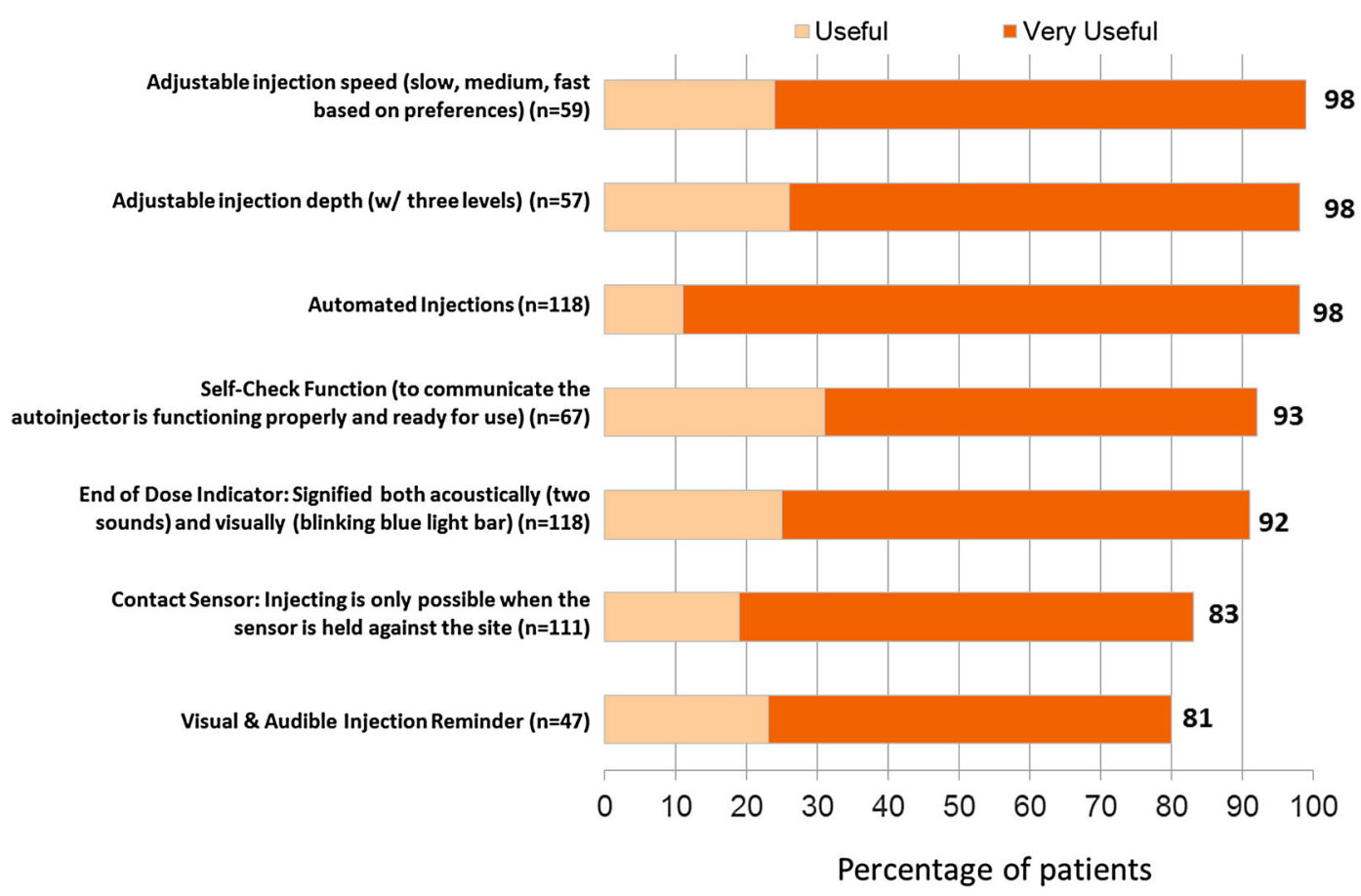

Fig. 4 Usefulness of BETACONNECT ${ }^{\mathrm{TM}}$ features. Base: respondents aware of/using feature and who did not answer "don't know"

reduces the chance of starting an injection by accident.

\section{Effect of BETACONNECT on the Patient Experience}

Participants using the various features of BETACONNECT largely agreed they had a beneficial effect on their injection experience (Fig. 6). Among those personalizing their injection depth $(n=57)$ and speed $(n=59)$, $88 \%$ and $81 \%$, respectively, thought that these features make injecting more comfortable. Moreover, 73\% agreed that the quietness and effortlessness of the BETACONNECT autoinjector reduced their level of anxiety about injecting. BETACONNECT also received positive ratings regarding its ease of handling: $92 \%$ agreed that the size and shape of BETACONNECT makes it easy to handle during injections and $68 \%$ thought that
BETACONNECT makes it easier to reach injection sites. Moreover, $67 \%$ agreed that the autoinjector decreases the level of injection site pain. These results also suggest that BETACONNECT may help improve compliance, as $80 \%$ of those using the reminder function thought they were less likely to miss an injection.

\section{DISCUSSION}

Interferon beta- $1 \mathrm{~b}$ is an injectable DMT with an established and favorable long-term safety and efficacy profile for patients with MS [22-24]. In addition, administration of DMTs using an autoinjector can reduce the number of adverse events such as injection site reactions, increase adherence to treatment, and improve patients' quality of life $[6,8,25]$. Whilst it is known that the use of an autoinjector is generally superior to manual injection for administering DMTs [6], 


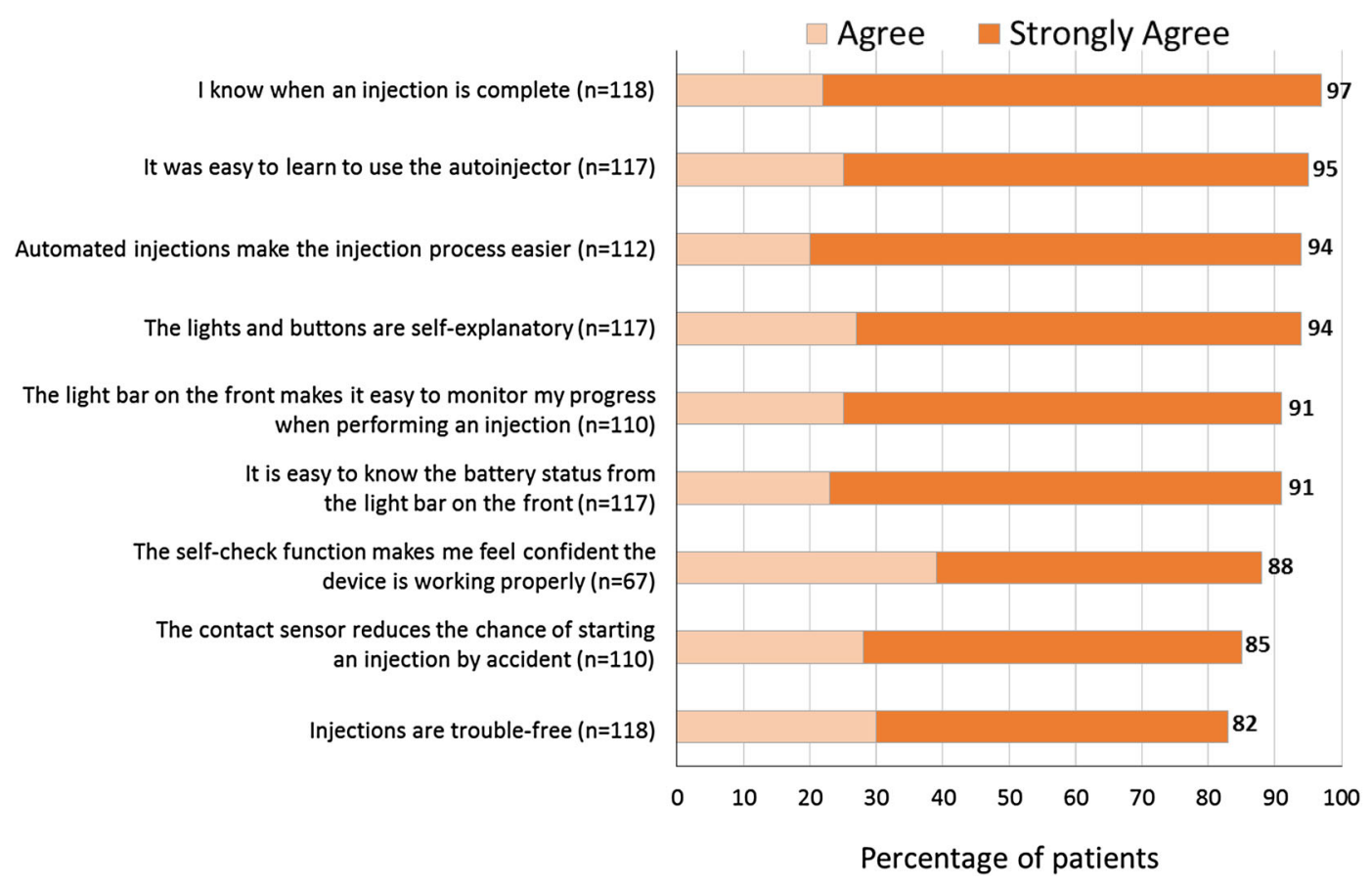

Fig. 5 Intuitiveness and ease of use of the autoinjector. Base: respondents aware of/using feature and who did not answer "don't know"

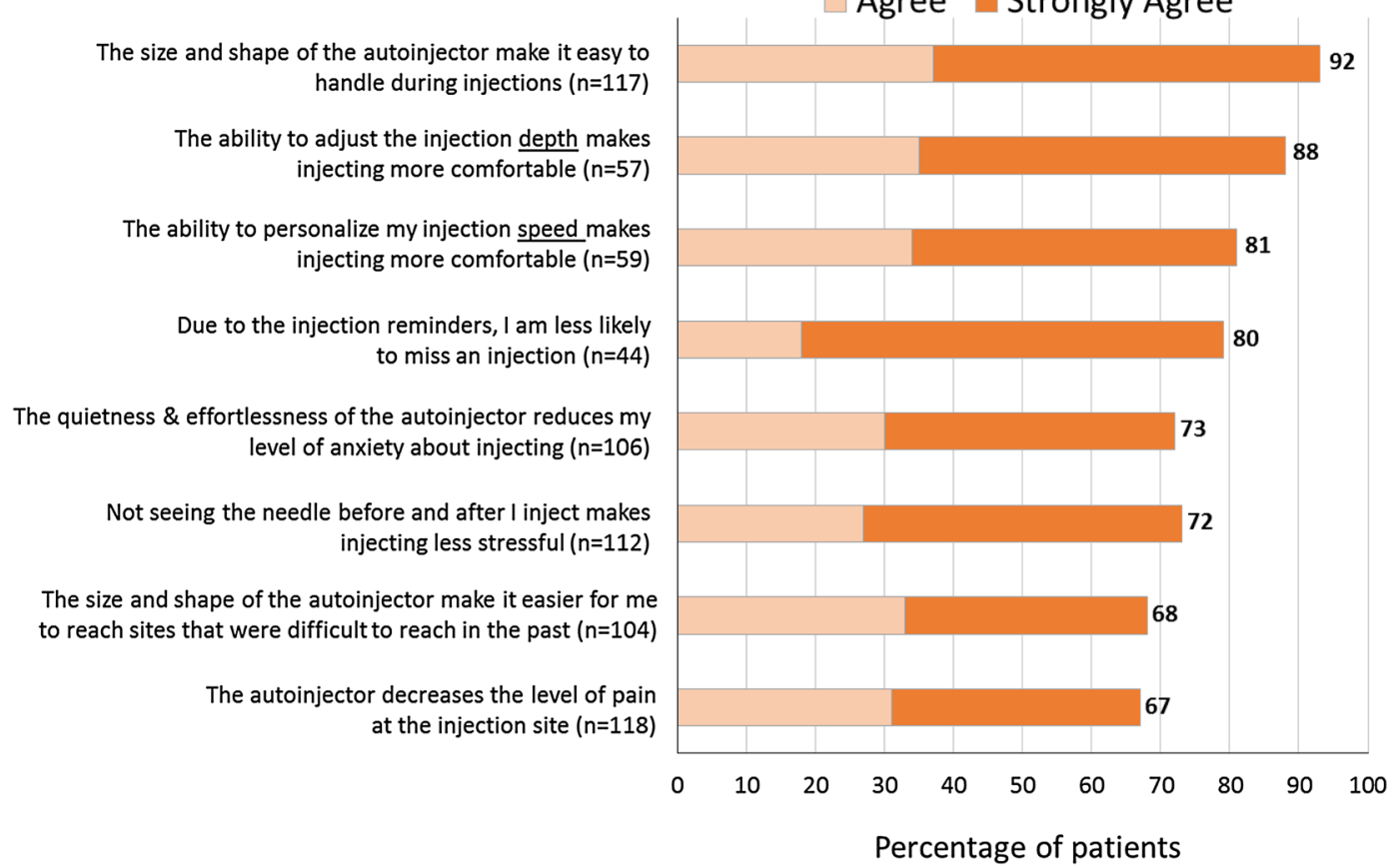

Fig. 6 Effect of BETACONNECT ${ }^{\mathrm{TM}}$ on the patient experience. Base: respondents aware of/using feature and who did not answer "don't know" 
ongoing improvements in autoinjector design represent additional opportunities to improve interferon beta-1b therapy. Two of the problems associated with most mechanical autoinjectors are the noise of operation and that the needle is not hidden after the injection process [19]. These issues may contribute to needle/injection phobia, and in fact a survey of patients with MS reported that among those using mechanical autoinjectors, most users (54\%) were unsatisfied or only moderately satisfied with their device [14]. As such, there is considerable scope to improve patients' injection experience, with many of these needs being met by the development of autoinjectors such as BETACONNECT. BETACONNECT features a fully electronic silent injection process and a needle that is hidden before, during, and after injection. Nevertheless, it is particularly important to measure patient satisfaction with new autoinjectors, such as BETACONNECT, as increased treatment satisfaction is associated with better adherence, as shown by numerous studies covering a wide range of medical conditions and treatments, including MS [21, 26]. For patients with MS, satisfaction with treatment (odds ratio [OR] 1.54; 95\% CI $1.20-1.98 ; P=0.0007)$ and ease of injection (OR 1.47; 95\% CI 1.15-1.87; $P=0.002$ ) were independent predictors of DMT adherence [21].

A patient satisfaction survey has recently been reported by Weller et al. [27] and forms the precursor to the current report. Weller et al. [27] surveyed the use of the BETACONNECT autoinjector in 1365 patients using a 13-question structured paper survey to gauge overall satisfaction with the device and the relative importance of its features. They found that $88 \%$ felt that the autoinjector was good or very good, $92 \%$ that it was helpful or very helpful, and $89 \%$ of respondents would most likely/probably recommend its use [27]. The current survey was conducted to further validate patient satisfaction with the BETACONNECT autoinjector and also to gain a much deeper understanding of the autoinjector's effect on patients' injection experience. Though only 118 patients completed the current survey, it was longer (lasting $15 \mathrm{~min}$ ), and more questions were answered and in greater depth, for example, using an open-ended question on reasons for satisfaction with BETACONNECT. It is known that quantitative patient satisfaction surveys benefit by supplementation with open response fields that allow patients to add free-text comments [28]. Free-text comments allow patients to think freely and communicate their opinions openly, and so may reflect something closer to an accurate patient experience than a reliance on structured questions and answers alone. Potential weaknesses of the current study are that it was performed in an uncontrolled setting and without a longitudinal follow-up, and had a relatively small sample size.

The overall results from the current survey show a preference for BETACONNECT over the previous device or method of injection and suggest that using the BETACONNECT autoinjector may increase satisfaction with treatment among patients on interferon beta-1b therapy. General impressions of using the BETACONNECT injector in the current survey were extremely favorable. These results are also in line with another study where "overall convenience" was cited by patients with MS as the most common benefit of using another autoinjector [29], whereas in other surveys better control of needle depth and injection speed was the most common response given as a desirable feature of autoinjectors for MS therapies [12, 14]. It is interesting to note that less skin irritation/pain and smoother injection were the second and 
third most common reasons given to be satisfied with BETACONNECT. This may reflect new BETACONNECT features such as its four-phase injection technology to help reduce the risk of an injection site reaction and its smooth fully electronic (rather than mechanical) operation.

\section{CONCLUSIONS}

Results from this study confirm the positive impact of the new BETACONNECT autoinjector and the relevance of its features in reducing injection site pain, promoting comfort, smooth injections, and ease of use, including improved ability to reach injection sites. As such, BETACONNECT represents a valid option for people that require interferon beta-1b injections for the improvement of their overall injection experience. More studies are currently underway to evaluate BETACONNECT with regard to patient adherence and persistence.

\section{ACKNOWLEDGMENTS}

This study and the article processing charges for this publication were funded by Bayer HealthCare Pharmaceuticals. The results of this survey were presented at the annual meeting of the Consortium of Multiple Sclerosis Centers, May 27-30, 2015, Indianapolis, IN, USA. All named authors meet the International Committee of Medical Journal Editors (ICMJE) criteria for authorship for this manuscript, take responsibility for the integrity of the work as a whole, and have given final approval to the version to be published. We would like to thank the BETAPLUS nurses in Germany for distributing the survey invitation cards, and their ongoing work supporting patients with MS. We also thank Thomas Schreiner, Ivonne Weller, and Julika Vogelreuter, Bayer Vital $\mathrm{GmbH}$, Leverkusen, for their ongoing support and important contributions to the study. Valuable consultation was provided throughout the project by Dr Gustavo Suarez (Bayer HealthCare Pharmaceuticals, Whippany, NJ, USA) and Dr Martina Sintzel (mcs medical communication services, Küsnacht, Switzerland). We are also grateful for medical writing services provided by Dr Richard Clark (freelance medical writer, Dunchurch, Warwickshire, UK). Support for this assistance was funded by Bayer HealthCare Pharmaceuticals.

Disclosures. Professor Ziemssen has received personal compensation for participating on advisory boards, trial steering committees and data and safety monitoring committees, as well as for scientific talks and project support from: Bayer HealthCare, Biogen Idec, Elan, Genzyme, Merck Serono, Novartis, Roche, Sanofi-Aventis, Synthon and Teva. Amy Perrin Ross has acted as a consultant/Advisory Board Member for Bayer Healthcare. Lauren Sylvester is an employee of Bayer HealthCare Pharmaceuticals, Whippany, NJ, USA. Mark Rametta is an employee of Bayer HealthCare Pharmaceuticals.

Compliance with ethics guidelines. All procedures followed were in accordance with the 1964 Declaration of Helsinki and its subsequent revisions. Informed consent was obtained from all patients included in the study. This article describes a non-interventional study, and so does not involve any new studies of human or animal subjects performed by any of the authors. 
Open Access. This article is distributed under the terms of the Creative Commons AttributionNonCommercial 4.0 International License (http://creativecommons.org/licenses/by-nc/4. $0 /$ ), which permits any noncommercial use, distribution, and reproduction in any medium, provided you give appropriate credit to the original author(s) and the source, provide a link to the Creative Commons license, and indicate if changes were made.

\section{REFERENCES}

1. Multiple Sclerosis International Foundation (MSIF). Atlas of MS 2013: mapping multiple sclerosis around the world. http://www.msif.org.

2. Degenhardt A, Ramagopalan SV, Scalfari A, Ebers GC. Clinical prognostic factors in multiple sclerosis: a natural history review. Nat Rev Neurol. 2009;5(12):672-82.

3. Weinshenker BG, Bass B, Rice GPA, et al. The natural history of multiple sclerosis: a geographically based study. 1. Clinical course and disability. Brain. 1989;112(1):133-46.

4. Plosker GL. Interferon- $\beta-1 b$ : a review of its use in multiple sclerosis. CNS Drugs. 2011;25(1):67-88.

5. Mikol D, Lopez-Bresnahan M, Taraskiewicz S, et al. A randomized, multicentre, open-label, parallel-group trial of the tolerability of interferon beta-1a (Rebif) administered by autoinjection or manual injection in relapsing-remitting multiple sclerosis. Mult Scler. 2005;11(5):585-91.

6. Brochet B, Lemaire G, Beddiaf A, et al. Reduction of injection site reactions in multiple sclerosis (MS) patients newly started on interferon beta $1 \mathrm{~b}$ therapy with two different devices. Rev Neurol (Paris). 2006;162(6-7):735-40.

7. Lugaresi A, Rottoli MR, Patti F. Fostering adherence to injectable disease-modifying therapies in multiple sclerosis. Expert Rev Neurother. 2014;14(9):1029-42.

8. Pozzilli C, Schweikert B, Ecari U, et al. Supportive strategies to improve adherence to IFN beta-1b in multiple sclerosis-results of the BetaPlus observational cohort study. J Neurol Sci. 2011;307:120-6.
9. Lugaresi A. Addressing the need for increased adherence to multiple sclerosis therapy: can delivery technology enhance patient motivation? Expert Opin Drug Deliv. 2009;6(9):995-1002.

10. Phillips JT, Fox E, Grainger W, Tuccillo D, Liu S, Deykin A. An open-label, multicenter study to evaluate the safe and effective use of the single-use autoinjector with an Avonex ${ }^{\circledR}$ prefilled syringe in multiple sclerosis subjects. BMC Neurol. 2011;11:126.

11. Devonshire V, Arbizu T, Borre B, et al. Patient-rated suitability of a novel electronic device for self-injection of subcutaneous interferon beta-1a in relapsing multiple sclerosis: an international, single-arm, multicentre, Phase IIIb study. BMC Neurol. 2010;10:28.

12. Bayas A, Japp G, Fulda U, Kallmann BA. Injection devices in MS therapy: survey on neurologists, MS-nurses and patients. Nervenheilkunde. 2010;29:57-62.

13. de Sa J, Urbano G, Reis L. Assessment of new application system in Portuguese patients with relapsing-remitting multiple sclerosis. Curr Med Res Opin. 2010;26(9):2237-42.

14. Verdun di Cantogno E, Russell S, Snow T. Understanding and meeting injection device needs in multiple sclerosis: a survey of patient attitudes and practices. Patient Prefer Adherence. 2011;5:173-180.

15. D'Arcy C, Thomas D, Stoneman D, Parkes L. Patient assessment of an electronic device for subcutaneous self-injection of interferon beta-1a for multiple sclerosis: an observational study in the UK and Ireland. Patient Prefer Adherence. 2012;6:55-61.

16. Johansson S, Ytterberg C, Claesson IM, et al. High concurrent presence of disability in multiple sclerosis. Associations with perceived health. J Neurol. 2007;254:767-73.

17. Valentine V, Kruger DF. Considerations in insulin delivery device selection. Diabetes Technol Ther. 2010;12(Suppl 1):S98-100.

18. Patti F. Cognitive impairment in multiple sclerosis. Mult Scler. 2009;15:2-8.

19. Lugaresi A. RebiSmart ${ }^{\mathrm{TM}}$ (version 1.5) device for multiple sclerosis treatment delivery and adherence. Expert Opin Drug Deliv. 2013;10(2):273-83.

20. Treadaway K, Cutter G, Salter A, et al. Factors that influence adherence with disease-modifying therapy in MS. J Neurol. 2009;256(4):568-76. 
21. Devonshire V, Lapierre $\mathrm{Y}$, Macdonell R, et al. The Global Adherence Project (GAP): a multicenter observational study on adherence to disease-modifying therapies in patients with relapsing-remitting multiple sclerosis. Eur J Neurol. 2011;18(1):69-77.

22. Ebers GC, Traboulsee A, Li D, et al. Analysis of clinical outcomes according to original treatment groups 16 years after the pivotal IFNB-1b trial. J Neurol Neurosurg Psychiatry. 2010;81(8):907-12.

23. Edan G, Kappos L, Montalban X, et al. Long-term impact of interferon beta-1b in patients with CIS: 8-year follow-up of BENEFIT. J Neurol Neurosurg Psychiatry. 2014;85(11):1183-9.

24. Reder AT, Oger JF, Kappos L, O'Connor P, Rametta M. Short-term and long-term safety and tolerability of interferon $\beta-1 \mathrm{~b}$ in multiple sclerosis. Mult Scler Relat Disord. 2014;3(3):294-302.

25. Pozzilli C, Schweikert B, Ecari U, Oentrich W, Bugge JP. Quality of life and depression in multiple sclerosis patients: longitudinal results of the BetaPlus study. J Neurol. 2012;259(11):2319-28.
26. Barbosa CD, Balp MM, Kulich K, Germain N, Rofail D. A literature review to explore the link between treatment satisfaction and adherence, compliance, and persistence. Patient Prefer Adherence. 2012;6:39-48

27. Weller I, Saake A, Schreiner T, Vogelreuter J, Petroff N. Patient satisfaction with the BETACONNECT ${ }^{\mathrm{TM}}$ autoinjector for interferon beta-1b. Patient Prefer Adherence. 2015;9:951-9.

28. Riiskjær E, Ammentorp J, Kofoed PE. The value of open-ended questions in surveys on patient experience: number of comments and perceived usefulness from a hospital perspective. Int J Qual Health Care. 2012;24(5):509-16.

29. Singer B, Wray S, Miller T, et al. Patient-rated ease of use and functional reliability of an electronic autoinjector for self-injection of subcutaneous interferon beta-1a for relapsing multiple sclerosis. Mult Scler Relat Disord. 2012;1(2):87-94. 